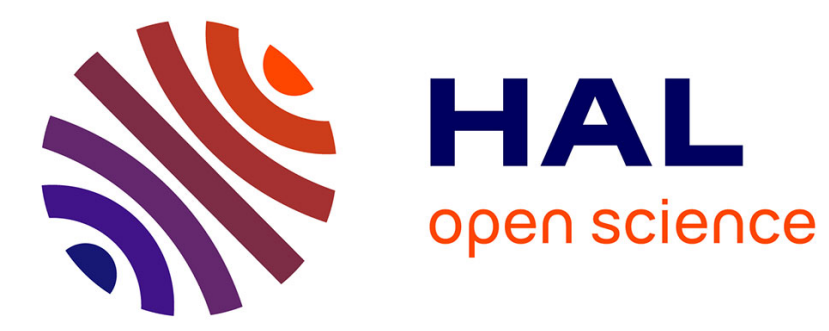

\title{
Defining the abatement cost in presence of learning-by-doing: application to the fuel cell electric vehicle
}

Anna Creti, Alena Kotelnikova, Guy Meunier, Jean-Pierre Ponssard

\section{To cite this version:}

Anna Creti, Alena Kotelnikova, Guy Meunier, Jean-Pierre Ponssard. Defining the abatement cost in presence of learning-by-doing: application to the fuel cell electric vehicle. 2015. hal-01158461

\author{
HAL Id: hal-01158461 \\ https://hal.science/hal-01158461
}

Preprint submitted on 1 Jun 2015

HAL is a multi-disciplinary open access archive for the deposit and dissemination of scientific research documents, whether they are published or not. The documents may come from teaching and research institutions in France or abroad, or from public or private research centers.
L'archive ouverte pluridisciplinaire HAL, est destinée au dépôt et à la diffusion de documents scientifiques de niveau recherche, publiés ou non, émanant des établissements d'enseignement et de recherche français ou étrangers, des laboratoires publics ou privés. 
DEFINING THE ABATEMENT COST IN PRESENCE OF LEARNING-BY-DOING:

APPLICATION TO THE FUEL CELL ELECTRIC VEHICLE

\author{
Anna CRETI \\ Alena KOTELNIKOVA \\ Guy MEUNIER \\ Jean-Pierre PONSSARD
}

May 2015

Cahier $n^{\circ}$ 2015-09

\title{
DEPARTEMENT D'ECONOMIE
}

Route de Saclay

91128 PALAISEAU CEDEX

(33) 169333033

http://www.economie.polytechnique.edu/

mailto:chantal.poujouly@polytechnique.edu 


\title{
Defining the Abatement Cost in Presence of Learning-by-doing: Application to the Fuel Cell Electric Vehicle.
}

\author{
Anna Creti ${ }^{a, b}$, Alena Kotelnikova ${ }^{a}$, Guy Meunier ${ }^{a, c}$, Jean-Pierre Ponssard $^{a, d}$ \\ ${ }^{a}$ Ecole Polytechnique \\ ${ }^{b}$ Université Paris Dauphine \\ ${ }^{c}$ INRA-UR1303 ALISS \\ ${ }^{d}$ CNRS
}

\author{
May 2015 \\ Preliminary draft
}

\begin{abstract}
The transition of a sector from a pollutant state to a clean one is studied. A green technology, subject to learning-by-doing, progressively replaces an old one. The notion of abatement cost in this dynamic context is fully characterized. The theoretical, dynamic optimization, perspective is linked to simple implementation rules. The practical "deployment" perspective allows to study sub-optimal trajectories. Moreover, the analysis of the launching date provides a definition of a dynamic abatement cost easy to use for evaluation of real-world policy options. The case of Fuel Cell Electric Vehicles offers an illustration of the proposed methodology.
\end{abstract}

JEL Classification: Q55, Q42, C61

Keywords: Dynamic abatement costs; learning by doing; fuel cell electric vehicles

*The authors would like to thank Michel Moreaux and Adrien Vogt-Schilb for their comments. Financial support from the Chair Energy et Prosperity at Fondation du Risque is gratefully acknowledged. 


\section{Introduction}

Marginal abatement costs (MACs) are both a conceptual and practical tool used in academic and policy discussions. The MAC is the cost to reduce polluting emissions at the margin, by a factory, a firm, a sector or a country. In policy discussions MACs are notably used to allocate decarbonisation efforts among sectors and arbitrage between technical options. This apparently simple definition may hide some difficulties. Whereas the theoretical concept and its practical use are consistent for short-term practices that reduce emissions, there might be some discrepancies for long-term reductions that necessitate sunk investments in physical and human capital along a dynamic process of deployment of a new technology. ${ }^{1}$ The objective of this paper is to propose an extension of the standard concept of static abatement costs to a dynamic one giving due consideration to the impact of learning-by-doing together with cost convexity.

Our analysis concerns a carbon-intensive sector in which an old polluting technology is progressively replaced by a new low-emitting technology. We shall use the substitution of fossil fuel by zero emissions vehicles as an illustration. Such a green transition is a dynamic process that requires to accumulate physical and human capital in several complementary goods (e.g. network of fueling stations, hydrogen production facilities, hydrogen cars). The pace at which this accumulation takes place is constrained, which can be explained by costs convexity. Furthermore, new technologies benefit from learning-by-doing or induced technical change. This latter phenomenon describes cost decrease as long as experience is accumulated and technological innovations are spread off. Technological learning has been observed historically for many different industries. In the basic model with a learning mechanism, technological progress is expressed in terms of decreasing specific costs of a technology as a function of cumulative production.

Several authors suggest learning curves as a meaningful presentation of technological change in global energy models (Loeschel, 2002). The existence of learning-by-doing in different renewable technologies is a central topic in the debate about $\mathrm{CO} 2$ abatement in electricity production. Even though the magnitude of learning-by-doing effect varies depending on whether they are measured at the national or the international level, there are no doubts that this phenomenon is relevant for the diffusion of carbon-free technologies. ${ }^{2}$ These dynamic aspects are often neglected in standard MACs calculations, as one ordinarily assumes a stable cost environment; investment cost and life duration are dealt through the notion of levelized costs. ${ }^{3}$

\footnotetext{
${ }^{1}$ Barker et al. (2006), Edenhofer et al. (2006), and Clapp et al. (2009) pointed out that induced technological change can significantly drive down MACs. Edenhofer et al. (2006) argues via a model comparison that the transformation to a carbon-free energy system can become stable as renewable energy technologies turn out to be cost-effective. Amann et al. (2009) similarly find that, as many other papers, technological progress impacts MAC curves.

${ }^{2}$ A survey of learning-by-doing rates for different energy technology can be found in IEA (2000) and Mc Donald and Schrattenholzer (2001). Learning rates varies from $25 \%$ for photovoltaics, $11 \%$ for wind power, and $13 \%$ for fuel cell in the period 1975-2000.

${ }^{3}$ Levelized costs are defined as the present value of the total cost of building and operating a generating plant over its economic life, converted to equal annual payments. This concept is frequently used to compare different technologies for electricity production.
} 
To properly introduce the cost dynamics we formulate the transition issue as the whole deployment phase of the new technology in substitution to an old polluting technology. We assume that emissions are subject to an environmental regulation through an exogenous CO2 price. We adopt a partial equilibrium framework and characterize the context in which the transition issue can indeed be addressed. We first characterize the optimal trajectory and highlight the difficulty to compute relevant MACs along this trajectory. Then we study second-best situations and determine a dynamic MAC. The dynamic abatement cost we calculate is both easy to interpret and implement for practical cases, even for sub-optimal trajectories. The theoretical analysis allows to identify the key assumptions required for its relevance.

The optimal trajectory, stemming from the minimization of the aggregate production costs of the overall cars fleet, is a smooth transition in which green cars progressively replace polluting ones. During the transition, the CO2 price should be equal to the sum of two terms: the difference between the cost of the marginal green car and a polluting car; and the learning benefits over the future. This result echoes the one by Goulder and Mathai (2000), who show analytically that the presence of induced technological change, both in the form of R\&D investments or learning-by-doing, always implies a lower time profile of optimal carbon taxes. At the end of the transition the fleet is completely green.

We then turn our analysis to our major contribution, i.e. addressing two operational questions. The first one concerns the date at which the new technology should be launched, and the second one the rate of its deployment. The deployment path of the carbon free technology is decomposed in different phases, encompassing the launching date up to the full substitution of the old polluting technology. We stress the role of cost assumptions in the overall diffusion process. The analysis of the launching date of a given deployment scenario, which does not necessarily coincide with the optimal scenario, provides a dynamic MAC. This dynamic MAC could be interpreted as the levelized cost of the whole deployment project.

We provide an application of our results to the transition from Internal Combustion Engine (ICE) vehicles to Fuel Cell Electric Vehicle (FCEV). This illustration is calibrated on data mainly describing the German market, where various initiatives to foster $\mathrm{H} 2$ cars actually exist. The deployment under consideration would be socially beneficial with a sequence of carbon prices starting at $53 € / \mathrm{t}$ in 2015 and reaching around $200 € / \mathrm{t}$ in 2050 (increasing at the social discount rate estimated at $4 \%$ ).

Several papers have already analyzed the role of cost convexity and the transition dynamic of polluting sectors. Vogt-Schilb et al. (2012) introduce convexities in the investment cost of clean capital in a multi-sector framework. They show that this convexity incites to spread investment in clean capital over time and comfort observed transition dynamics. Similarly, Amigues et al. (2015) introduce convexity in the form of adjustment cost in clean capital accumulation to study the transition from non-renewable to renewable resources. The role of convexity has also been stressed by Bramoullé and Olson (2005) in their study of the role of learning-by-doing in sectoral arbitrage. Without convexities, learning-by-doing alone does not justify a ramping of the clean option and learning cost should be postponed as far as possible. If production cost are convex, a progressive increase of the abatement in a sector is optimal. Amigues et al. (2014) analyze the optimal timing of carbon capture and storage policies under increasing returns to scale. They show that the carbon capture of the emissions 
should start earlier than under a constant average cost assumption. Compared to these contributions, our perspective is more operational. We consider sub-optimal deployment scenarios and provide a convenient generalization of the static abatement cost to a dynamic one which encompasses the whole transition phase.

Our approach can also be related to other streams of literature, as macro models on innovation and green technologies, on one side, and large scale computable models on the other. Analytical macro models that recommend early deployment of green technologies remain imprecise on the specific sectoral cost assumptions that would justify their conclusions (e.g. Grimaud and Rouge, 2008; Acemoglu et al., 2012). Top-down computable general equilibrium (CGE) models (as for instance GEM-E3, GREEN, PACE and MITEPPA) are typically based on exogenous technological change, where roadmaps from polluting to carbon free technologies are used. The associated cost function of the carbon free technologies are time dependent. They compare long term scenarios under various environmental constraints. ${ }^{4}$ Bottom-up models are almost exclusively technology snapshot models that examine a suite of technological alternatives over time. A number of bottom-up models have integrated endogenous technological change that assumes the existence of learning by doing. Examples are MESSAGE, MARKAL and POLES. Both bottom-up and top-down large-scale models provide valuable numerical results, but they require ad hoc solvable optimization techniques which make them unsuitable for conceptual analysis. Our analysis and its application to the hydrogen car deployment provides a link between these two streams of literature. It facilitates the conceptual analysis of the main cost assumptions and its interpretability for decision makers.

The paper is organized as follows. Section 2 presents the analytical model and develops the first best and second best scenarios. Section 3 illustrate the application to the case of FCEV versus ICE, whereas Section 4 briefly concludes.

\section{The analytical framework}

\subsection{The model}

We consider a simple model of a sector, say the car sector, the size of which is constant. There are two varieties of vehicles: cars build by using an old polluting technology (ICE vehicle) and new ones which are carbon free (FCEV vehicle). The new technology is subject to learning by doing.

Time is continuous from 0 to $+\infty$. The discount rate is constant equal to $r$. We consider that cars last one unit of time. There are $N$ cars among which $x$ new "green" cars and $N-x$ polluting old cars. Units are normalized so that each old car emits one unit of $\mathrm{CO}_{2}$, green cars do not pollute. The cost of a old car is constant: $c_{o}$. The cost of $x$ new green cars is a function of the knowledge capital $X: C(X, x)$. At any time $t \in[0,+\infty$ [ the knowledge capital $X_{t}$ is equal to the total quantity of green cars previously built $X_{t}=\int_{0}^{t} x_{t} d t$.

The cost $C(X, x)$ is assumed twice differentiable and positive. It is null for $x=0$, for all $X: C(X, 0)=0, \forall X$, and strictly positive otherwise. The cost is increasing and convex

\footnotetext{
${ }^{4}$ See for instance Rösler et al. (2014) which relies the bottom-up energy systems ETSAP-TIAM family of models (Loulou and Labriet, 2008; Loulou, 2008).
} 
with respect to $x$, the quantity of green cars produced. Knowledge reduces the production cost and this effect is lower for larger knowledge stock. The marginal production cost also decreases with knowledge. All this assumptions translate formally:

$$
\frac{\partial C}{\partial x} \geq 0, \frac{\partial C}{\partial X} \leq 0, \frac{\partial^{2} C}{\partial x^{2}}>0, \frac{\partial^{2} C}{\partial X^{2}}>0 \text { and } \frac{\partial^{2} C}{\partial X \partial x} \leq 0
$$

To ensure the convexity of the problem we assume that the cost convexity:

$$
\left[\frac{\partial^{2} C}{\partial X \partial x}\right]^{2}<\frac{\partial^{2} C}{\partial X^{2}} \frac{\partial^{2} C}{\partial x^{2}} .
$$

Finally, we assume that the effect of knowledge on the marginal cost is larger for larger production. Said differently, the derivative $\partial C / \partial X$ is concave with respect to $x$.

The price of $\mathrm{CO}_{2}$ is $p_{t}^{C O 2}$, it grows at the speed of the discount rate $p_{t}^{C O 2}=e^{r t} p_{0}$. This assumption will prove very useful to simplify dynamic considerations. It means that once discounted a $\mathrm{CO}_{2}$ emissions has the same value whatever the date at which it is emitted. Such a price dynamics could be linked to the stock nature of $\mathrm{CO}_{2}$ emissions and the low decay of $\mathrm{CO}_{2}$ in the atmosphere. It would occur if there was a constraint on the total cumulated emissions (it would be a $\mathrm{CO}_{2}$ Hotelling's rule), or an environmental cost proportional to the stock of emissions and no decay.

A notation that will prove useful is the discounted cost of a fully green fleet with a initial knowledge stock $X$. This cost is the discounted sum of the costs of producing $N$ green cars at each time. With this production schedule the knowledge stock at time $t$ is $X+t N$ so this discounted cost, denoted $\Omega(X)$, is as follows:

$$
\Omega(X)=\int_{0}^{+\infty} e^{-r t} C(X+t N, N) d t
$$

\subsection{The optimal trajectory}

The objective of the social planner is to minimize the cost:

$$
\begin{array}{cc}
\Gamma=\int_{0}^{+\infty} e^{-r t}\left[\left(p_{t}^{C O 2}+c_{o}\right) .\left(N-x_{t}\right)+C\left(X_{t}, x_{t}\right)\right] d t & \text { s.t. } \\
\dot{X}_{t}=x_{t} & \lambda_{t} \\
0 \leq x_{t} \leq N & \theta_{t}, \delta_{t} .
\end{array}
$$

Greek letters are the Lagrange coefficients, in current $€$, associated to each constraint. The dynamics of the optimal trajectory is qualitatively simple: there are three different regimes whether $x_{t}$ is null, equal to the total number of cars $N$ or in between.

The following Proposition describes the features of the optimal trajectory. 
Proposition 1 The production of green cars increases over time. There are two dates $T_{s}$ and $T_{e}$, with $T_{s} \leq T_{e}$, at which the transition respectively starts and ends:

$$
\begin{gathered}
x_{t}=0 \text { for } t \leq T_{s} \\
0<x_{t}<N \text { for } T_{s}<t<T_{e} \\
x_{t}=N \text { for } t \geq T_{e}
\end{gathered}
$$

During the transition, that is, for $t \in\left[T_{s}, T_{e}\right]$ the following equation holds:

$$
p_{t}^{C O 2}=\underbrace{\left[C_{x}\left(X_{t}, x_{t}\right)-c_{o}\right]}_{\text {static abatement cost }}+\underbrace{\int_{t}^{+\infty} e^{-r(\tau-t)} C_{X}\left(X_{\tau}, x_{\tau}\right) d \tau}_{\text {learning benefit }(<0)}
$$

Proof. The main step of the proof consists in proving that $x_{t}$ is increasing if $x_{t} \in(0, N)$. This condition ensures that once $x_{t}>0$ the number of cars cannot come back to zero, and that $x_{t}$ does not move when $x_{t}=N$. If $x_{t}$ is strictly positive $\left(\theta_{t}=0\right)$ and lower than the total car fleet $\left(\delta_{t}=0\right)$, along an optimal deployment trajectory the following equations hold:

$$
\begin{aligned}
C_{x}\left(X_{t}, x_{t}\right)-c_{o} & =p_{t}^{C O 2}+\lambda_{t} \\
\dot{\lambda}_{t}-r \lambda_{t} & =C_{X}\left(X_{t}, x_{t}\right) .
\end{aligned}
$$

If $x_{t} \in(0, N)$, taking the time derivative of the first equation gives:

$$
\begin{aligned}
C_{x X} \dot{X}_{t}+C_{x x} \dot{x}_{t} & =\dot{p}_{t}^{C O 2}+\dot{\lambda}_{t} \\
C_{x X} x_{t}+C_{x x} \dot{x}_{t} & =\dot{p}_{t}^{C O 2}+r \lambda_{t}+C_{X} \\
C_{x x} \dot{x}_{t} & =\dot{p}_{t}^{C O 2}+r \lambda_{t}+\left[C_{X}\left(X_{t}, x_{t}\right)-C_{x X} x\right]
\end{aligned}
$$

The last term of the right hand side of the second equation is positive because $C_{X}(X, x)$ is concave with respect to $x$ (so the derivative in the bracketed term is positive) and $C_{X}(X, 0)=$ 0 . Therefore, $x_{t}$ is increasing through time, $\dot{x}_{t} \geq 0$.

Then, since the $\mathrm{CO}_{2}$ price increases exponentially, $x_{t}$ cannot be always null along an optimal trajectory. Then either $x_{0}=0$ or $x_{0}>0$. In the latter case $T_{s}=0$, whereas in the former case $T_{s}$ is the inf of the dates at which $x_{t}>0$.

The optimal trajectory is a smooth transition in which green cars progressively replace old cars. At the end of the transition the fleet is completely green. During the transition, the fraction of the fleet that is green is determined by equation (3). According to this equation, at a time $t$ the price of $\mathrm{CO}_{2}$ should be equal to the sum of two terms, which can be interpreted as the relevant marginal abatement cost in period $t$. The first bracketed term is the "static" marginal abatement cost, that is the difference between the cost of the marginal green car and an old car. The second term, the integral, is negative and represents the learning benefits, that is, the reduction of future cost due to the production of one more green car today.

It is important to stress that the relevant marginal abatement cost, the right hand side of equation (3), depends on the whole time path of car production. It depends on the number of cars previously built, via the knowledge stock, and it depends on the future 
production schedule. Thus, the relevant marginal abatement cost at a particular date cannot be computed regardless of the whole trajectory. Even in our simple model, it is difficult to derive a simple rule, such as the comparison between abatement cost and $\mathrm{CO}_{2}$ price, for determining the optimal production at each point in time.

Learning-by-doing plays the role of the inter-temporal glue in the present model, as the accumulation of a knowledge stock explains that each period abatement decision cannot be taken independently of decisions taken at other dates.

Considering two extreme cases is useful to interpret the role of our cost assumptions in the time dependency. On the one hand, without learning-by-doing, the static abatement cost is sufficient to determine the number of green cars at each date. There is a smooth transition. Still, each date can be isolated from the rest of the trajectory: there is no interdependency between past, present and future decisions. On the other hand, without convexity, the transition takes place at once at some date to be determined which can be determined through some generalization of the notion of abatement cost. This is pointed out by the following corollary.

Corollary 1 If $C_{x x}=0$ then the optimal strategy is to replace all old cars by new cars from a date $T_{s}=T_{e}$. At this date the $\mathrm{CO}_{2}$ price is:

$$
p_{T s}^{C O 2}=\frac{r \Omega(0)-c_{o} N}{N} .
$$

in which $\Omega(0)$ is given by equation (1).

Proof. If $C_{x x}=0$, given that $C(X, 0)=0, C_{X}(X, x)=C_{X x}(X, x) x$. Then, we resort by reductio ad absurdum assuming $T_{s}<T_{e}$. Between the two dates the equation (3) is satisfied and taking its derivative with respect to $t$ gives:

$$
\begin{aligned}
\dot{p}_{t}^{C O 2} & =C_{X x} \dot{X}_{t}+C_{x x} \dot{x}_{t}-\dot{\lambda}_{t} \\
& =C_{X x} x_{t}-C_{X}\left(X_{t}, x_{t}\right)+r\left[\int_{t}^{+\infty} e^{-r(\tau-t)} C_{X}\left(X_{\tau}, x_{\tau}\right) d \tau\right] \\
0>\dot{p}_{t}^{C O 2} & =r\left[\int_{t}^{+\infty} e^{-r(\tau-t)} C_{X}\left(X_{\tau}, x_{\tau}\right) d \tau\right] \leq 0
\end{aligned}
$$

Therefore, the number of green cars jumps from 0 to $N$ at date $T_{s}=T_{e}$, and the total discounted cost $\Gamma$ could be written as a function of the date $T_{s}$ :

$$
\Gamma=\int_{0}^{T_{s}} e^{-r t}\left[\left(p_{t}^{C O 2}+c_{o}\right) \cdot N\right] d t+e^{-r T_{s}} \Omega(0)
$$

Along the optimal trajectory, $T_{s}$ should minimize this function. Taking the derivative with respect to $T_{s}$ in the equation above and setting it equal to zero gives the equation (6).

The threshold of $\mathrm{CO}_{2}$ price in the equation (6) could be interpreted as a MAC for the whole technical option: it is the ratio of the difference between the levelized (static) cost of a fleet of green cars and a fleet of old cars to the quantity of emissions abated by the project. In the next subsection, this rule is extended to a general cost function and a ramping deployment scenario. 
These results recall those already obtained in the literature. Vogt-Schilb et al. (2012) have analyzed how the convexity of the investment cost may impact the transition rates in a multi sector framework. Bramoullé and Olson (2005) also pointed out that absent convexity, the transition is instantaneous (their Proposition 1 p. 1941).

Ordinarily the effect of learning-by-doing on the timing and costs of emissions abatement remains unclear. Learning-by-doing clearly reduces the costs of future abatement. This suggests delaying abatement activities. However, there is added value to current abatement. It contributes to cumulative experience and hence helps reduce the costs of future abatement. It is unclear which of these two effects dominates (Goulder and Mathai, 2000). For instance, Manne and Richels (2004) and Manne and Barreto (2004), using the top down CGE model MERGE, find that for a wide range of stabilization ceilings, a gradual transition away from the "no policy" emissions baseline is preferable to one that requires substantial near-term reductions.

In our model, the impact of learning by doing is analytically displayed along the optimal deployment trajectory. However, the ambiguity of choosing earlier or later abatement remains. In particular, we characterize suboptimal deployment patterns. If the deployment cost is not minimized or the total number of green cars produced during deployment is larger than the optimal one, the launching date of the green car should be postponed. If the total number of green cars produced during deployment is slightly lower than the optimal one, the launching should instead take place earlier.

\subsection{The "deployment" perspective}

In the optimal scenario, the whole trajectory is consistent with the $\mathrm{CO}_{2}$ price: the date at which the deployment starts and the pace at which green cars replace old cars are jointly determined. For a real world application, this theoretical analysis does not provide a simple rule to evaluate a technical option and a "launching date". Furthermore, for real world issues there are many components in the cost (e.g. investment in infrastructure) that do not easily translate into a specified version of $C(X, x)$ so that the determination of an optimal trajectory may be out of reach. It is more realistic to discuss suboptimal trajectories.

We propose to decompose the global problem into sub-problems easier to connect to practical examples, offering straightforward interpretations. We disentangle the choice of the production schedule of cars during the deployment phase from the choice of a date at which deployment should start (the date $T_{s}$ in the optimal scenario). More precisely, the global problem could be decomposed as follow. There is a "deployment scenario" of the green option with a finite duration; during this deployment a exogenously given amount of green cars is produced each year. The "launching date" of this deployment should be determined. Once deployment is achieved, the whole fleet is replaced by green cars. The optimal trajectory can be found by choosing simultaneously and consistently not only the launching date, but also the deployment scenario characteristics. The optimal choice of the deployment scenario is discussed in the next subsection. We consider here a given scenario, regardless that optimal choice.

For a given deployment scenario, the only variable to be chosen is the launching date $T_{l}$ that should balance the price of $\mathrm{CO}_{2}$ with the abatement cost of the deployment. Waiting one year to launch the deployment increases emissions by an amount proportional to the fleet 
but postpones the costly deployment and implementation of the green fleet. The discounted cost of the fleet, given by equation (2), can be decomposed to reflect this trade-off. To do so, the costs of the deployment and the fully green fleet should be discounted to be independent of the launching date:

- The deployment scenario takes place over $D$ years during which a total quantity of $\bar{X}$ cars are produced. The trajectory of accumulation is $\left(\xi_{\tau}\right)_{\tau \in[0, D]}$ in which $\xi_{\tau}$ is the number of green cars produced at stage $\tau$ of the deployment (i.e. $\tau$ years after the launching), and $\bar{X}=\int_{0}^{D} \xi_{\tau} d \tau$. The cost of this deployment is

$$
I=\int_{0}^{D} e^{-r \tau}\left[C\left(\bar{X}_{\tau}, \xi_{\tau}\right)-c_{o} \xi_{\tau}\right] d \tau \text { in which } \bar{X}_{\tau}=\int_{0}^{\tau} \xi_{u} d u
$$

- At the end of the deployment the fleet is completely green, and the discounted cost of the green fleet of cars solely depends on $\bar{X}$, the knowledge accumulated during the deployment. This cost, view from the date of the end of the deployment, is $\Omega(\bar{X})$ given by equation (1).

The discounted cost of the fleet, given by equation (2), can then be written (with a slight abuse of notation):

$$
\Gamma\left(T_{l}\right)=\underbrace{\int_{0}^{T_{l}+D} e^{-r t}\left(c_{o}+p_{t}^{C O 2}\right) N d t}_{\text {fully old fleet }}+\underbrace{e^{-r T_{l}} I-p_{0} \bar{X}}_{\text {deployment phase }}+\underbrace{e^{-r\left(T_{l}+D\right)} \Omega(\bar{X})}_{\text {fully green fleet }} .
$$

This cost is the sum of three terms: the cost, including the $\mathrm{CO}_{2}$ cost, of a fleet of old cars from today to the end of the deployment; the cost of the deployment minus the gain from abatement during deployment; once deployment is achieved the fleet is entirely green and the current cost of the fully green fleet only depends on the quantity of knowledge accumulated during the deployment.

The problem is now simply to determine the date $T_{l}$ at which the deployment should be launched. The assumption that the $\mathrm{CO}_{2}$ price grows at the interest rate plays a key role here because the precise date at which carbon reduction takes place does not influence welfare. The emissions abated during deployment, which are precisely equal to the quantity of cars accumulated during the deployment, do not modify the choice of the launching date. This nicely fits our decomposition, since the choice of the launching date only influences costs via discounting.

Proposition 2 The optimal launching date $T_{l}^{*}$ of the deployment trajectory $\left(\xi_{\tau}\right)$ is such that:

$$
P_{T_{l}^{*}}^{C O 2}=\frac{r I}{N}+\frac{r \Omega(\bar{X})-c_{0} N}{N} e^{-r D}
$$


Proof. Taking the derivative of the discounted total cost $\Gamma$ given by (8) with respect to the launching date gives:

$$
\begin{aligned}
\frac{\partial \Gamma}{\partial T_{l}} & =e^{-r\left(T_{l}+D\right)}\left(c_{o}+p_{T_{l}+D}^{C O 2}\right) N-r I e^{-r T_{l}}-r \Omega(\bar{X}) e^{-r\left(T_{l}+D\right)} \\
& =e^{-r T_{l}}\left[p_{0} e^{r T_{l}} N+c_{o} e^{-r D}-r I-r \Omega(\bar{X}) e^{-r D}\right]
\end{aligned}
$$

At the optimal launching date this derivative is null and, consequently, equation (9) is satisfied.

This rule can be easily interpreted: the launching date is chosen so that the abatement cost of the whole project is equal to the $\mathrm{CO}_{2}$ price. The abatement cost of the project is the sum of two components: the sunk cost of the deployment that takes $D$ years $\left(\frac{r I}{N}\right)$; and the relative discounted over-cost of a green car at the end of the deployment $\left(\frac{r \Omega(\bar{X})-c_{0} N}{N} e^{-r D}\right)$. The cost $r \Omega(\bar{X})$ is the annualized cost of a fully green fleet, so $r \Omega(\bar{X}) / N$ is the average current cost of a green car over the life of the green fleet. Note that, if at the end of the deployment the green car cost is linear and stable $(C(X, x)=\underline{c} x)$ the second component becomes the difference between the cost of a green and an old car $\left(\underline{c}-c_{0}\right)$.

The price obtained in Corollary 1 corresponds to the price of Proposition 2 for an extreme deployment scenario in which there is no ramping of the production, that is when $\bar{X}=0$ and $D=0$, we have that $I=0$.

\subsection{The optimal trajectory revisited and some comparative statics}

The deployment approach can be seen as a convenient procedure to compute to the optimal trajectory. Indeed, in the optimal trajectory there is a deployment phase during which green cars progressively replace old cars, and after this phase the whole fleet is green (cf Proposition 1). If the deployment scenario is precisely similar to the optimal deployment, then the launching dates coincide ( $T_{s}$ in Lemma 1 equals $T_{l}$ in Proposition 2).

The optimal trajectory can be found with a deployment approach by proceeding as follows. For any quantity $\bar{X}$ and duration $D$ there is a deployment scenario that minimizes the discounted cost $I$ (given by equation 7 ). This deployment scenario is independent of the $\mathrm{CO}_{2}$ price and the launching date. Let us denote $I^{*}(\bar{X}, D)$ the minimum deployment cost which is only defined for $D \geq \bar{X} / N$ :

$$
\begin{aligned}
I^{*}(\bar{X}, D) & =\min _{x_{\tau}} \int_{0}^{D} e^{-r \tau}\left[C\left(X_{\tau}, x_{\tau}\right)-c_{0} x_{\tau}\right] d \tau \\
\text { s.t. } \dot{X}_{t} & =x_{\tau} ; 0 \leq x_{\tau} \leq N \text { and } X_{D}=\bar{X}
\end{aligned}
$$

The optimal solution is found by optimally choosing three variables: the launching date, the duration of deployment $D$ and the quantity $\bar{X}$ of green cars produced during this deployment. The optimal trajectory corresponds to the trajectory found by minimizing with respect to $T_{l}, \bar{X}$ and $D$ the following cost:

$$
\Gamma=\int_{0}^{T_{l}+D} e^{-r t}\left(c_{o}+p_{t}^{C O 2}\right) N d t+e^{-r T_{l}} I^{*}(\bar{X}, D)-p_{0} \bar{X}+e^{-r\left(T_{l}+D\right)} \Omega(\bar{X}) .
$$


The optimal quantity of green cars produced during deployment and the optimal duration of the deployment satisfy the pair of first order conditions:

$$
\begin{aligned}
p_{0} e^{r T_{l}} & =\frac{\partial I^{*}}{\partial \bar{X}}+e^{-r D} \frac{\partial \Omega}{\partial \bar{X}} \\
p_{0} e^{r T_{l}} N-e^{-r D}\left[r \Omega-c_{0} N\right] & =-\frac{\partial I^{*}}{\partial D}
\end{aligned}
$$

Consider first equation (12) that determines the choice of the optimal number of green cars during deployment. The left-hand-side is the gain due to the reduction of emissions during the deployment. This benefit should be equalized with the marginal cost of the overall project. This marginal cost is the sum of the marginal cost of the deployment and the marginal latter cost of the fully green, post-deployment, fleet. The former is positive and the latter is negative, since an increase of the quantity of green car produced during deployment reduces the cost of the fully green fleet.

The choice of the optimal duration as represented by equation (13), equalizes the gain from reducing the deployment duration with the corresponding marginal cost $\left(\partial I^{*} / \partial D<\right.$ $0)$. Reducing the duration of deployment allows to save $N$ additional emissions but brings forward the replacement of the old fleet by a green one.

It is feasible to briefly examine how the sub-optimality of a deployment scenario impacts the launching date. ${ }^{5}$

Proposition 3 An optimal trajectory can be described by an optimal deployment scenario and the associated optimal launching date. The optimal deployment scenario consists in $\bar{X}^{*}$, $D^{*}$ and $\left(\xi_{\tau}^{*}\right)_{\tau \in\left[0, D^{*}\right]}$.

If the deployment scenario is suboptimal:

- If the deployment cost is not minimized $\left(\xi_{\tau} \neq \xi_{\tau}^{*}\right)$, the launching should be postponed;

- If the total number of green cars produced during deployment is larger than the optimal one $\left(\bar{X}>\bar{X}^{*}\right)$, the launching should be postponed;

- If the total number of green cars produced during deployment is slightly lower than the optimal one $\left(\bar{X}<\bar{X}^{*}\right)$, the launching should take place earlier.

If, given $\bar{X}$ and duration $D$, the deployment cost $I$ is not minimized, then the launching should be postponed. Indeed, the higher the cost of the project the higher the associated $\mathrm{CO}_{2}$ price.

If the duration is fixed and the cost is minimized, the choice of $\bar{X}$ has a non monotonic effect on the choice of the launching date. Figure 1 illustrates the joint determination of the launching date and the quantity of accumulated cars. Figure 1(a) represents the result of Proposition 2: the abatement cost of the whole project should be equalized to the launching date. This is also true for a sub-optimal scenario, notably if $\bar{X} \neq \bar{X}^{*}$. Figure 1(b) depicts the choice of the quantity of green cars accumulated during deployment that should equalize the marginal cost of such accumulation with the $\mathrm{CO}_{2}$ price at the launching date.

\footnotetext{
${ }^{5} \mathrm{~A}$ formal proof of the following proposition is available upon request.
} 


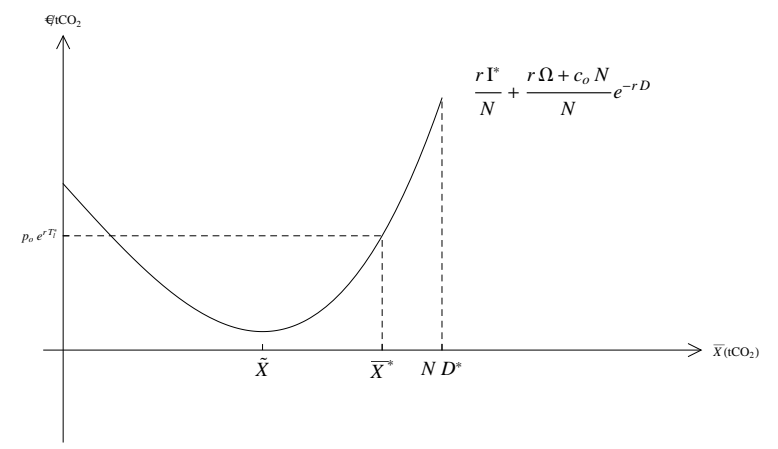

(a) The choice of the launching date $T_{l}^{*}$ equalizes the $\mathrm{CO}_{2}$ price with the levelized cost of the project

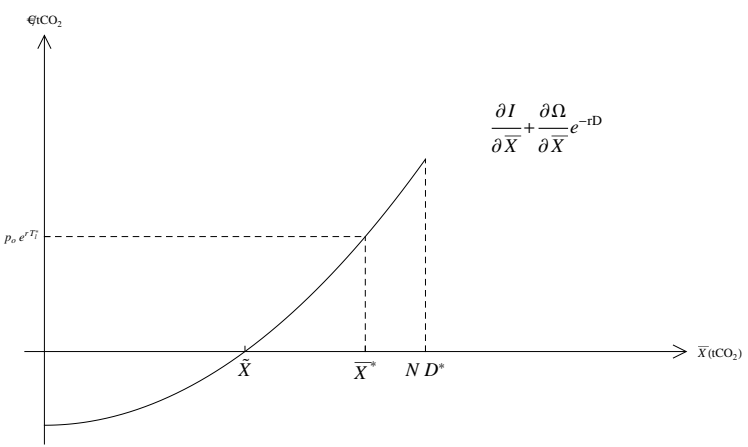

(b) The choice of the quantity of green cars produced during the deployment $\bar{X}^{*}$, equalizes the marginal cost with the $\mathrm{CO}_{2}$ price

Figure 1: The joint determination of the launching date (a) and the quantity of cars produced during deployment (b).

As illustrated by Figure 1(a), the accumulation $\bar{X}$ that would minimize the launching date is lower than the optimal accumulation. So, if more cars than optimal are accumulated, the launching should be postponed, because of the increased cost of the whole deployment. If the number of accumulated cars is smaller than the optimal one, but not far from it, the cost is actually reduced and launching should start earlier than the optimal date. This earlier deployment would partly compensates for the lower interim abatement.

The figure 1(b) also shows how the accumulation of green cars during deployment is modified by a sub-optimal launching date. The later the launching is the larger the accumulation should be.

\section{Application to the case of FCEV versus ICE}

The case of Fuel Cell Electric Vehicles (FCEV) for the substitution of the mature ignition combustion engine (ICE) provides an interesting illustration of our methodology. FCEV have attracted a lot of attention in view of their potential for the reduction of carbon emissions in the transport system. There exists a number of studies on this subject. Among them a study (McKinsey \& Company, 2010) developed scenarios for the deployment of PHEV, BEV and FCEV in Europe over the period 2013-2050. This study concludes that the total cost of ownership (TCO) for all power-trains are expected to converge around 2040. Bruegel and the European School for Management and Technology revisit the economic rationale for public action for FCEV (Zachmann et al., 2012). Rösler et al. (2014) carry an in depth investigation using the energy bottom-up model TIAM-ECN (Loulou, 2008; Loulou and Labriet, 2008) to build scenarios up to 2100 for passenger car transportation in Europe. They show that FCEV could achieve most of the market in 2050 if no significant breakthrough in battery is made. In contrast Oshiro and Masui (2014) analyze the Japan market and show that BEV would take most of the passenger car market in 2050 while the share of FCEV would remain marginal. In all these studies the relative cost dynamics for FCEV plays a crucial role in an intricate way so the results are not easily interpretable for decision makers. 
At the other extreme comparing the TCOs of FCEV versus ICE with the respective $\mathrm{CO}_{2}$ emissions to get a first cut of the abatement cost for FCEV is quite convenient. ${ }^{6}$ However since the cost of FCEV exhibits a sharp decrease this abatement cost will also decrease over time this approach is too simplistic. The methodology developed in this paper provides an extension of the static abatement cost that precisely takes into account the cost dynamics of the trajectory. We recall the key assumptions:

- An exogenous deployment for FCEV based on industry projections; this deployment is based on a number of technical and economic constraints such as the time to achieve the targeted cost projections, the time to build up the network, social constraints such as acceptability of the new technology by consumers... Once this deployment scenario is characterized it becomes meaningful to model the associated cost dynamics based on a limited number of parameters.

- A normative social price of carbon based on global general equilibrium models. More precisely we assume a $\mathrm{CO}_{2}$ price sequence increasing at the social discount rate from a given initial value.

From these two assumptions we are able to answer the following two questions:

- What should be the threshold $\mathrm{CO}_{2}$ price in 2015 so that it would be optimal to launch the proposed deployment of FCEV over the period 2015 to 2050? We shall refer to this price as the dynamic abatement cost of the deployment trajectory.

- If the dynamic abatement cost is higher than the current normative cost of carbon in 2015, what is the magnitude of the changes in the key parameters in our model that would make the abatement cost consistent with the normative value?

The corresponding results can be used to determine with industry experts the technical feasibility and uncertainties associated with different sets of assumptions.

\subsection{The data and the associated static abatement costs}

Table 1 gives the data. The geographic context is Germany, a country in which some significant moves have already been made in favor of FCEV. The cost dynamics underlying the deployment scenario involves three main components: manufacturing costs, infrastructure costs and fuel costs. The corresponding model is detailed in Creti et al. (2015). We briefly review the construction of the cost function.

The total passenger car fleet in Germany is assumed to increase from today's level of 47 million vehicles to 49.5 million in 2030. It is assumed to be stable from 2030 to 2050 . Our exogenous deployment scenario assumes a very progressive ramp up starting in 2015 up to a $2.7 \%$ market share in 2030 and a targeted market share of $15 \%$ in 2050, that is 7.500 million units for the FCEV car park. Based on this scenario one constructs a unit manufacturing cost for a FCEV. Cars are expected to have a ten year life time, so that

\footnotetext{
${ }^{6}$ Static abatement costs are routinely used in a number of policy papers. See for instance for a discussion of the merits of hydrogen Beeker (2014).
} 
the actual yearly production takes account the renewal of the car park. Both ICE and FCEV cars are running $15000 \mathrm{~km}$ per year. Fuel consumption is derived based on energy efficiency. Using unit fuel costs one gets the total fuel consumption. Fuel costs for hydrogen depend on the technology to produce hydrogen (development and capital expenditures of energy producers are integrated in this cost). ${ }^{7}$ The cost of infrastructure is derived from the number of hydrogen refueling stations (HRS) which is derived from the required network to deliver the total hydrogen consumption at every time period. Delivery cost to the stations is added to the infrastructure cost. Gasoline price is also the delivery price at the retail station. In the base case we assume that value added taxes on the cost components are not included but that the excise tax on imported petroleum is, since it represents an opportunity cost for importing oil. Note that the excise tax is in absolute value so its percentage of the gasoline price declines over time. The untaxed gasoline price follows the oil price in the world market, assumed to increase at a constant rate of $1.4 \%{ }^{8} \quad \mathrm{CO}_{2}$ emissions depend both on energy efficiency (which keeps improving for ICE and FCEV) and the progressive introduction of carbon free technologies for hydrogen production.

\begin{tabular}{|c|c|c|c|c|c|c|}
\hline & Unit & 2015 & 2020 & 2025 & 2030 & 2050 \\
\hline $\begin{array}{c}\text { Market size } \\
\text { (car life time: } 10 \text { years, } 15000 \mathrm{~km} / \mathrm{yr} \text { ) }\end{array}$ & 1000 cars & 1 & 95 & 453 & 1350 & 7500 \\
\hline \multicolumn{7}{|l|}{ Vehicle manufacturing cost } \\
\hline FCEV & $\mathrm{k} €$ & 60.0 & 37.7 & 32.1 & 28.6 & 22.8 \\
\hline $\mathrm{ICE}$ & $\mathrm{k} €$ & 22.0 & 21.4 & 21.3 & 21.1 & 20.5 \\
\hline Relative price FCEV vs ICE & $\%$ & $173 \%$ & $77 \%$ & $53 \%$ & $37 \%$ & $13 \%$ \\
\hline \multicolumn{7}{|l|}{ Fuel costs } \\
\hline \multicolumn{7}{|l|}{ FCEV } \\
\hline $\begin{array}{l}\text { Hydrogen production cost } \\
\text { (delivery cost to HRS included) }\end{array}$ & $€ / \mathrm{kg}$ & 7.0 & 5.8 & 6.1 & 6.3 & 6.8 \\
\hline Hydrogen consumption per $100 \mathrm{~km}$ & $\mathrm{~kg} / 100 \mathrm{~km}$ & 0.95 & 0.87 & 0.84 & 0.80 & 0.70 \\
\hline \multicolumn{7}{|l|}{$\mathrm{ICE}$} \\
\hline Gasoline price & $€ / 1$ & 1.30 & 1.35 & 1.40 & 1.46 & 1.71 \\
\hline of which state tax (w/o VAT) & $\%$ & $50 \%$ & $48 \%$ & $47 \%$ & $45 \%$ & $38 \%$ \\
\hline Gasoline consumption per $100 \mathrm{~km}$ & $1 / 100 \mathrm{~km}$ & 7.04 & 6.2 & 4.97 & 4.88 & 4.8 \\
\hline \multicolumn{7}{|l|}{ Infrastructure costs } \\
\hline Number of HRS & $\#$ & 40 & 220 & 926 & 2234 & 9257 \\
\hline Capital cost per unit of car & $\mathrm{k} €$ & 62.24 & 2.39 & 2.02 & 1.65 & 1.18 \\
\hline \multicolumn{7}{|l|}{$\mathrm{CO}_{2}$ emissions } \\
\hline Hydrogen & $\mathrm{kgCO}_{2} / 100 \mathrm{~km}$ & 9.0 & 6.2 & 5.0 & 3.8 & 1.7 \\
\hline Gasoline & $\mathrm{kgCO}_{2} / 100 \mathrm{~km}$ & 19.8 & 17.4 & 14.0 & 13.7 & 13.5 \\
\hline
\end{tabular}

Table 1: Simplified Data Sheet

\footnotetext{
${ }^{7}$ In our scenario we shall consider three new technologies: carbon sequestration and capture, electrolysis based on renewable energies, and biogas.

${ }^{8}$ The average gasoline market price per litre in Germany in 2014 was equal to 1,6 $€($ including all taxes). While the recent drop in oil prices had a significant impact on this price, its long term impact for year 2030 and later is uncertain. The $1.4 \%$ annual growth rate is consistent with IEA long term projections.
} 
For each cost component we introduced a learning by doing parameter and calibrated the model using costs estimates based on existing applied studies and interviews with industry experts. In this way we can analyze how the results are affected through small changes in the cost and environmental parameters. This will be convenient for sensitivity analysis.

Figure 2 gives the TCO at various dates with its cost components. Observe that introducing an excise tax on hydrogen in 2050 would not endanger its position relative to ICE. Figure 3 compares our values for TCO with those obtained in Rösler et al. (2014). Figure 4 depicts fuel efficiency for FCEV and ICE. ${ }^{9}$ Figure 5 gives the respective $\mathrm{CO} 2$ emissions for FCEV and ICE. ${ }^{10}$

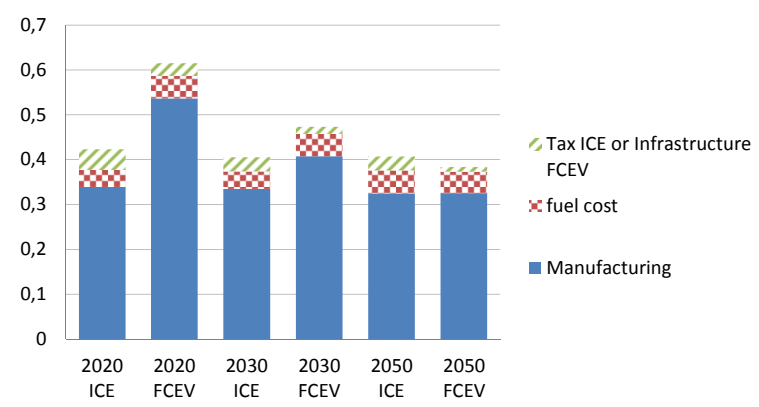

Figure 2: Analysis of the costs components for one car unit in $€$ per $\mathrm{km}$ per year

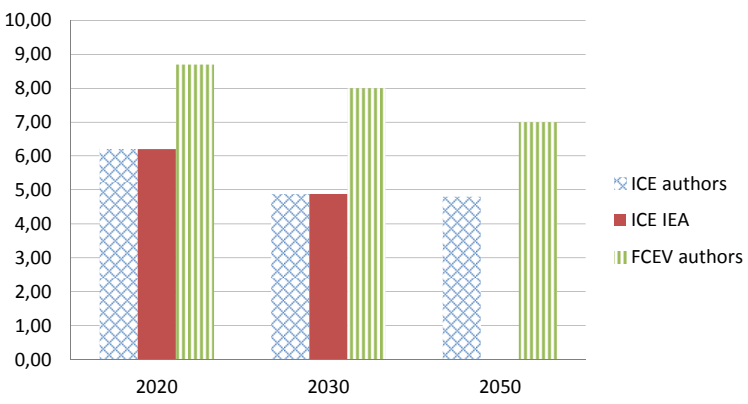

Figure 4: Fuel consumption ICE $(\mathrm{l} / 100 \mathrm{~km}) \mathrm{FCEV}(\mathrm{kg} / 10 \mathrm{~km})$

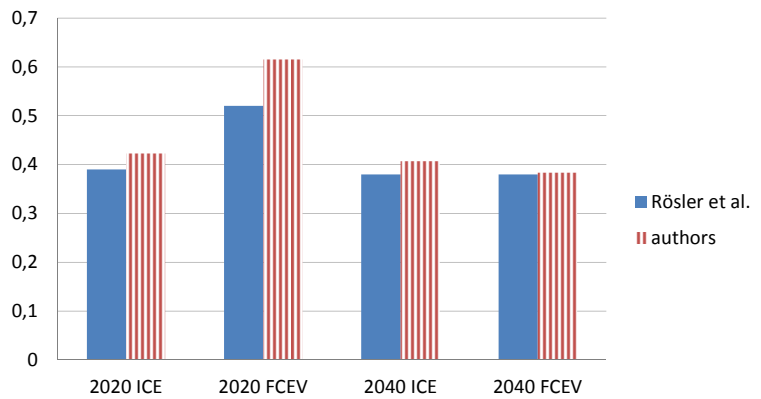

Figure 3: TCO authors versus Rösler et al. (2014), in $€$ per km per year

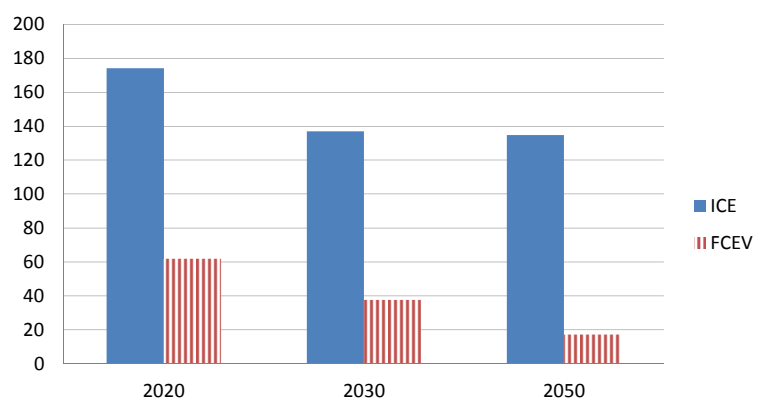

Figure 5: $\mathrm{CO}_{2}$ emissions $\mathrm{g} / \mathrm{km}$

From the respective TCOs and from the respective yearly $\mathrm{CO}_{2}$ emissions we can derive the yearly static abatement costs (Proposition 1). They are depicted Figure 6. It starts around $1600 € / \mathrm{t}$ in 2020 and decreases to zero in 2043 (the year at which the relative total cost

\footnotetext{
${ }^{9}$ For ICE the sources are coming from the EIA Annual Energy Outlook 2014 (http://www.eia.gov/forecasts/aeo/pdf).

${ }^{10}$ Note that for FCEV the level of carbon free electrolysis in the portfolio of technologies grows from $15 \%$ in 2020 to $40 \%$ in 2050 which explains the decline in CO2 emissions. The values for ICE are higher than the EU targets. These targets apply to the average portfolio of car manufacturers while FCEV would be more for large vehicles (C/D or J segments).
} 


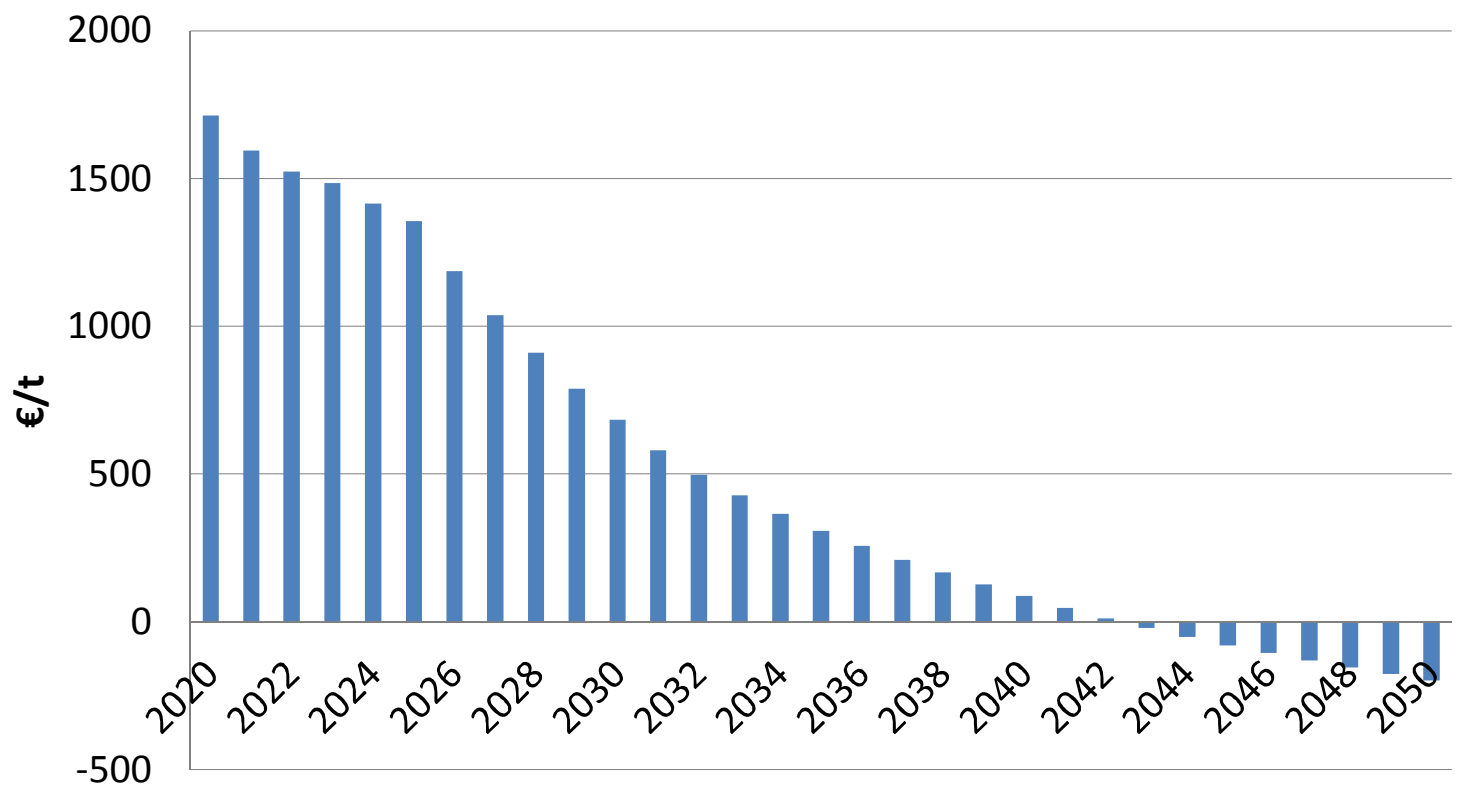

Figure 6: Static abatement cost $(€ / \mathrm{t})$

of ownership becomes positive for FCEV). Not much can be inferred from this sequence of abatement costs. In contrast our methodology provides a relevant proxy for policy analysis.

\subsection{The dynamic abatement cost for the FCEV deployment tra- jectory}

Recall the result of Proposition 2:

$$
p_{0} e^{r T_{l}^{*}}=\frac{r I}{N}+\left[\frac{r \Omega}{N}-c_{0}\right] e^{-r D}
$$

Our illustration directly fits for applying this result with one exception: the TCO and the $\mathrm{CO} 2$ emissions for ICE are not constant over time but slightly decreasing. Proposition 2 provides a first order estimate and a more refined approach should take this assumption into account. To calculate our first order estimate we proceed as follows.

- Time is discrete and not continuous;

- The launching date is such that $T_{l}^{*}=2015$ and the deployment is completed at $T_{l}^{*}+D=$ 2050;

- TCOs are assumed to converge at the end of the deployment phase which implies $\left[\frac{r \Omega}{N}-c_{0}\right]=0$

- The CO2 avoided emissions for year 2050 and further is not $N$ but the park times the difference in emissions per unit of car, all values being taken at date 2050 . 
Altogether this gives the following result.

Corollary 2 The dynamic abatement cost $p_{2015}^{C O 2}$ for the reference scenario is such that:

$$
p_{2015}^{C O 2}=((1-\delta) / \delta) I_{2015-2050} / A_{2050}
$$

in which: - $I_{2015-2050}$ is the total discounted cost of the trajectory over the period 20152050; - $A_{2050}$ denotes the yearly avoided emissions at full deployment that is in year 2050; $\delta=1 /(1+r)$ with $r$ standing for the social discount rate.

This expression can be interpreted as an extension of the static abatement cost in which a once and for all investment with a capex of $I_{2015-2050}$ at date 2050 with an infinite life time will balance a recurring amount $A_{2050}$ of avoided $\mathrm{CO}_{2}$ emissions.

Based on the data of Table 1 and using a $4 \%$ social discount rate we obtain a numerical value for $p_{2015}^{C O 2}=53 € / \mathrm{t}$. If we assume an initial social cost of carbon around $30 € / \mathrm{t}$ for 2015, as suggested by Quinet (2009) and Quinet (2013) for France, this suggests that our reference scenario should be postponed until 2030. Since this scenario starts quite slowly it is more meaningful to investigate how one could strengthen some parameters of our model to achieve an optimal launching date at 2015. This leads to the following target analysis.

\subsection{Target analysis}

Our methodology delivers a simple and attractive tool to explore how the change in the parameters of our model affects the dynamic abatement cost. This exploration can be made so as to achieve a target value for this abatement cost, say $30 € / \mathrm{t}$ in 2015 .

Corollary 3 To achieve a dynamic abatement cost $p_{2015}^{C O 2}$ consistent with a social cost of carbon of $30 € / t$ in 2015 one may either target for

- a market share of $27 \%$ rather than $15 \%$ in the total car park in 2050;

- a growth rate of $2.9 \%$ instead of $1.4 \%$ in the increase in the oil price;

- a higher learning rate for manufacturing costs so that the unit cost of a FCEV car be only $6.7 \%$ instead of $13 \%$ higher than the one of a ICE car in 2050;

- a higher learning rate for H2 production costs so that the unit cost of H2 production be $33 \%$ lower than the expected value with the reference scenario in 2050.

Consider the following four parameters as well as a combination of changes in these four parameters. The detailed results of this exploration are given Table 2. Note that all one parameter changes impact the total investment cost while a change in the targeted market size and in the hydrogen production cost (modeled as a decrease in the cost of the electrolysis process combined with a more intensive use of this technology) also impact the level of $\mathrm{CO}_{2}$ avoided in 2050. The changes may appear quite large but the effort can be substantially reduced if they are combined. Indeed as shown in Table 2 the targeted abatement cost could be achieved with: 
- a market share of $20 \%$ in the total car park in 2050 ;

- a growth rate of $1.8 \%$ in the increase in the oil price;

- a unit cost of a FCEV car $9.8 \%$ higher than the one of a ICE car in 2050;

- a unit cost of $\mathrm{H} 2$ production $8 \%$ lower than the expected value with the reference scenario in 2050 .

In Figure 7 the effort of the combined change relative to the one parameter changes is depicted.

\begin{tabular}{|c|c|c||c|c|c|c|c|}
\hline & unit & $\begin{array}{c}\text { Base } \\
\text { Case }\end{array}$ & $\begin{array}{c}\text { Market size } \\
\text { in of total } \\
\text { car park }\end{array}$ & $\begin{array}{c}\text { Gasoline } \\
\text { price } \\
\text { (yearly rate } \\
\text { of increase) }\end{array}$ & $\begin{array}{c}\text { Manufacturing } \\
\text { cost (FCEV vs } \\
\text { ICE in 2050) }\end{array}$ & $\begin{array}{c}\text { Hydrogen } \\
\text { production } \\
\text { cost in 2050 }\end{array}$ & $\begin{array}{c}4 \\
\text { parameter } \\
\text { target }\end{array}$ \\
\hline \hline $\begin{array}{c}\text { Market size } \\
\text { (in of total car park) }\end{array}$ & $\%$ & $15 \%$ & $\mathbf{2 7 \%}$ & $15 \%$ & $15 \%$ & $15 \%$ & $\mathbf{2 0 \%}$ \\
\hline $\begin{array}{c}\text { Gasoline price } \\
\text { (yearly rate of increase) }\end{array}$ & $\%$ & $1.4 \%$ & $1.4 \%$ & $\mathbf{2 . 9} \%$ & $1.4 \%$ & $1.4 \%$ & $\mathbf{1 . 8} \%$ \\
\hline $\begin{array}{c}\text { Manufacturing cost } \\
\text { (FCEV vs ICE in } 2050)\end{array}$ & $\%$ & $11.3 \%$ & $11 . \%$ & $11.3 \%$ & $\mathbf{6 . 7} \%$ & $11.3 \%$ & $\mathbf{9 . 8} \%$ \\
\hline $\begin{array}{c}\text { Hydrogen } \\
\text { production cost }\end{array}$ & $€ / \mathrm{kg}$ & 6.8 & 6.8 & 6.8 & 6.8 & $\mathbf{4 . 5}$ & $\mathbf{6 . 2}$ \\
\hline \hline $\begin{array}{c}\text { avoided CO } \text { emissions } \\
\text { in 2050 }\end{array}$ & $\mathrm{Mt} / \mathrm{year}$ & 13.2 & 18.9 & 13.2 & 13.2 & 13.8 & 14.1 \\
\hline $\begin{array}{c}\text { Discounted cost } \\
\text { for the scenario up to } 2050\end{array}$ & $\mathrm{M} €$ & 17511 & 14001 & 9719 & 9965 & 10528 & 10582 \\
\hline $\begin{array}{c}\text { Dynamic } \\
\text { abatement cost }\end{array}$ & $€ / \mathrm{t}$ & 53 & 30 & 30 & 30 & 30 & 30 \\
\hline
\end{tabular}

Table 2: Target analysis, each column correspond to a scenario in which a parameter is changed to get a dynamic abatement cost of $30 € / \mathrm{t}$, in the last column all four parameters are changed.

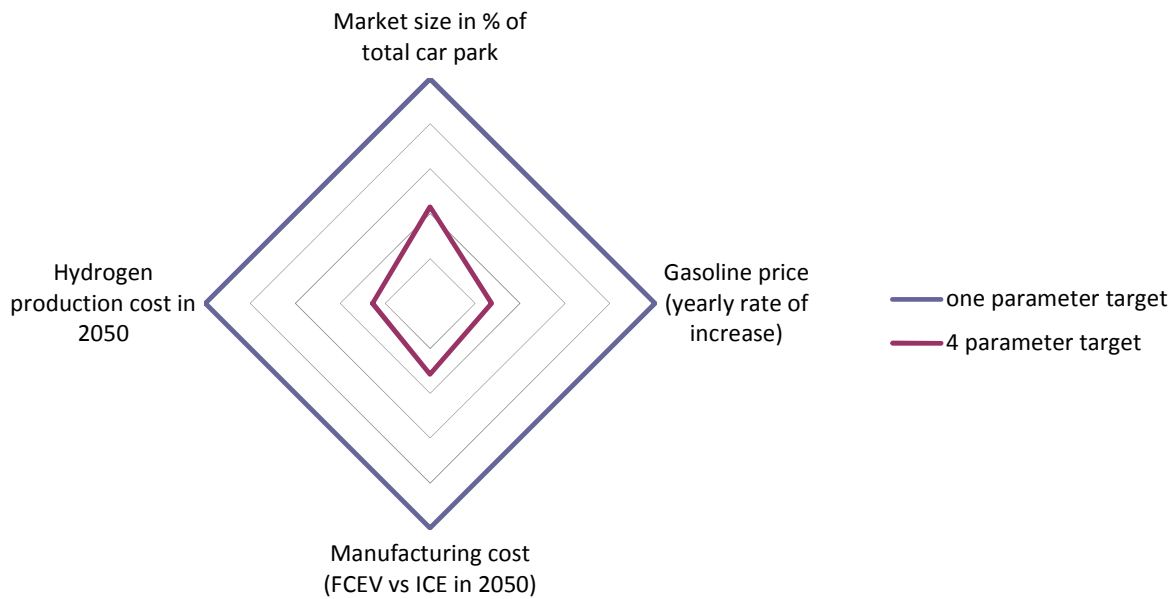

Figure 7: The four parameters target in $\%$ of the one parameter ones 


\section{Conclusion}

This paper considers the transition of a sector from a pollutant state to a clean one. The sector consists of a given number of dirty units (say a car park), to be progressively replaces by clean ones. The production cost of clean units involves learning by doing and convexities with respect to the instantaneous rate of production. Along the optimal trajectory the CO2 price equals the static abatement cost plus some learning benefit, which is common in this type of model. While simple as a matter of principle this result fails in delivering the optimal deployment strategy without specifying further the cost function.

The main contribution of the paper consists in designing a decomposition methodology to disentangle the choice of the production schedule from the choice of launching date in the search of the optimal trajectory. This leads to two interesting results. Firstly we extend the standard static notion of abatement cost associated to the substitution of a dirty unit by a clean one at some point of time to a dynamic one in which the all deployment trajectory is globally considered from its launching date. Second this dynamic abatement cost is also meaningful for a second best trajectory, which is often the case in applications where trajectories are defined through industrial and social considerations outside the scope of the modelling exercise. These results provide a simple framework for policy guidance. This is illustrated through an analysis of a trajectory in which ICE are progressively replaced by FCEV.

It would be interesting to extend this approach in several directions. We assumed stationarity of the cost function for the dirty units, a less extreme assumption may be more appropriate to accommodate efficiency gains and changes in the associated input prices. A more elaborate extension would consider the simultaneous deployment of alternative clean technologies such as BEV and FCEV to be substituted to ICE. This may possibly involve the introduction of consumers'preferences in which the role of product differentiation could be analyzed. Another interesting extension would be to consider the decentralization issue of the optimal trajectory to the various players (manufacturers, H2 producers, network operators). These players need operate under a positive profit constraint assumptions. We have assumed an exogenous normative CO2 price. There is no guaranty that the transfer of externality benefit to the players can be enough to accommodate the positive profit constraints. Defining more operational policy instruments could be examined such as imposing a minimal rate of clean cars in the portfolio of manufacturers. We think that some answers to these various questions could be obtained while preserving the simplicity of our approach.

\section{References}

Acemoglu, D., Aghion, P., Bursztyn, L. and Hemous, D. (2012). The environment and directed technical change, American Economic Review 102(1): 131-66.

Amann, M., Rafaj, P., Höhne, N. and von Winterfeldt, D. (2009). Ghg mitigation potentials in annex i countries: Comparison of model estimates for 2020, Interim Report, International Institute for Applied Systems Analysis .

Amigues, J.-P., Ayong Le Kama, A. and Moreaux, M. (2015). Equilibrium transitions 
from non-renewable energy to renewable energy under capacity constraints, Journal of Economic Dynamics and Control 55: 89 - 112.

Amigues, J.-P., Lafforgue, G. and Moreaux, M. (2014). Optimal timing of ccs policies under decreasing returns to scale, Technical report, Toulouse School of Economics (TSE).

Barker, T., Pan, H., Köhler, J., Warren, R. and Winne, S. (2006). Decarbonizing the global economy with induced technological change: scenarios to 2100 using e3mg, The Energy Journal pp. 241-258.

Beeker, E. (2014). Y a-t-il une place pour l'hydrogène dans la transition énergétique ?, Note d'analyse, France Stratégie, Commissariat général à la Stratégie et à la Prospective.

URL: http://www.strategie.gouv.fr/sites/strategie.gouv.fr/files/atoms/files/201-08-06nafs-hydrogene-hd.pdf

Bramoullé, Y. and Olson, L. J. (2005). Allocation of pollution abatement under learning by doing, Journal of Public Economics 89(9): 1935-1960.

Clapp, C., Karousakis, K., Buchner, B. and Chateau, J. (2009). National and sectoral ghg mitigation potential.

Creti, A., Kotelnikova, A., Meunier, G. and Ponssard, J.-P. (2015). A cost benefit analysis of fuel cell electric vehicles, Report 1: 1-41.

Edenhofer, O., Lessmann, K., Kemfert, C., Grubb, M. and Köhler, J. (2006). Induced technological change: Exploring its implications for the economics of atmospheric stabilization: Synthesis report from the innovation modeling comparison project, The Energy Journal pp. $57-107$.

Goulder, L. H. and Mathai, K. (2000). Optimal $\mathrm{CO}_{2}$ abatement in the presence of induced technological change, Journal of Environmental Economics and Management 39(1): 1-38.

Grimaud, A. and Rouge, L. (2008). Environment, directed technical change and economic policy, Environmental and Resource Economics 41(4): 439-463.

Loulou, R. (2008). ETSAP-TIAM: the TIMES integrated assessment model. part II: mathematical formulation, Computational Management Science 5(1-2): 41-66.

Loulou, R. and Labriet, M. (2008). ETSAP-TIAM: the TIMES integrated assessment model Part I: Model structure, Computational Management Science 5(1-2): 7-40.

Manne, A. and Richels, R. (2004). The impact of learning-by-doing on the timing and costs of CO2 abatement, Energy Economics 26(4): 603-619.

Manne, A. S. and Barreto, L. (2004). Learn-by-doing and carbon dioxide abatement, Energy Economics 26(4): 621-633.

McKinsey \& Company, A. (2010). Portfolio of powertrains for europe: a fact-based analysis. 
Oshiro, K. and Masui, T. (2014). Diffusion of low emission vehicles and their impact on co 2 emission reduction in japan, Energy Policy p. In press.

Quinet, A. (2009). La valeur tutélaire du carbone, Rapport du Centre d'Analyse Stratégique, La documentation Française.

Quinet, E. (2013). L'évaluation socioéconomique des investissements publics, Commisariat général à la stratégie et à la prospective.

Rösler, H., van der Zwaan, B., Keppo, I. and Bruggink, J. (2014). Electricity versus hydrogen for passenger cars under stringent climate change control, Sustainable Energy Technologies and Assessments 5: 106-118.

Vogt-Schilb, A., Meunier, G. and Hallegatte, S. (2012). How inertia and limited potentials affect the timing of sectoral abatements in optimal climate policy, World Bank Policy Research Working Paper (6154).

Zachmann, G., Holtermann, M., Radeke, J., Tam, M., Huberty, M., Naumenko, D. and Faye, A. N. (2012). The great transformation: decarbonising Europe's energy and transport systems., Bruegel Blueprint 16. 